\title{
Initial survey of PLA2G6 missense variant causing neuroaxonal dystrophy in Papillon dogs in North America and Europe
}

\author{
Karthik Raj and Urs Giger ${ }^{*}$ (D)
}

\begin{abstract}
Background: An autosomal recessive, rapidly progressive degenerative neuropathy known as infantile neuroaxonal dystrophy (NAD) was originally reported in Papillion puppies in 1995. In 2015, a causative missense variant in the PLA2G6 gene was identified in three affected puppies. Archived samples from Papillons clinically diagnosed with NAD prior to 2015 as well as samples obtained from 660 Papillons from North America and Europe between 2015 and 2017 were screened for the presence of this PLA2G6 gene variant (XM_022424454.1:c.1579G > A) using a TaqMan assay.

Results: Archived samples from affected puppies diagnosed prior to 2015 and three more recently acquired samples from Papillons clinically affected with NAD were all homozygous for the variant. SIFT analysis predicts that the PLA2G6 missense substitution (XP_022280162.1:p.Ala527Thr) will not be tolerated in the iPLA $\beta$ protein. Notably, $17.5 \%$ of the 660 tested Papillons were heterozygotes, resulting in a variant allele frequency of 0.092 in this initial survey. Since then, screening for NAD in Papillons by at least 10 other laboratories and data from the Health Committee of Papillon Club of America gathered between 2017 and 2019 reveal a variant allele frequency of 0.047.

Conclusions: This survey and data from other laboratories documents the widespread presence of the PLA2G6 variant in the Papillon population in North America and Europe. Despite the apparent declining prevalence of the PLA2G6 variant, screening of Papillons intended for breeding is still recommended to avoid inadvertent production of puppies with infantile NAD.
\end{abstract}

Keywords: Canine, Mutations, Screening, Breeding, Ataxia

\section{Plain English summary}

Infantile neuroaxonal dystrophy (NAD) is a rare rapidly progressive disease first reported in Papillion dogs in 1995. Clinical manifestations of ataxia, head tremor, difficulty rising, discordant gate, limb extension, paresis, inability to prehend food and water, and blindness are observed by 1-3 months of age. A specific genetic variant in PLA2G6 was recently identified in three Papillons with NAD in Japan. We screened Papillons with a

\footnotetext{
* Correspondence: giger@vet.upenn.edu

Section of Medical Genetics (PennGen Laboratories), School of Veterinary Medicine, University of Pennsylvania, 3900 Delancey St., Philadelphia, PA 19104-6010, USA
}

clinical diagnosis of NAD received prior to 2015 and samples from an additional 660 Papillons from North America and Europe received between 2015 and 2017 for the presence of this gene variant. All samples from Papillons clinically affected with NAD were homozygous for the variant. Furthermore, $17.5 \%$ of all Papillons tested were asymptomatic heterozygotes, and therefore able to pass on the variant to their offspring. Since 2017, an increasing number of laboratories offer NAD screening of Papillons, often together with progressive retinal atrophy testing. Data obtained between 2017 and 19 indicates a variant allele frequency of 0.047 . While all these surveys are biased, the apparently high prevalence

(c) The Author(s). 2020 Open Access This article is licensed under a Creative Commons Attribution 4.0 International License, which permits use, sharing, adaptation, distribution and reproduction in any medium or format, as long as you give appropriate credit to the original author(s) and the source, provide a link to the Creative Commons licence, and indicate if changes were made. The images or other third party material in this article are included in the article's Creative Commons licence, unless indicated otherwise in a credit line to the material. If material is not included in the article's Creative Commons licence and your intended use is not permitted by statutory regulation or exceeds the permitted use, you will need to obtain permission directly from the copyright holder. To view a copy of this licence, visit http://creativecommons.org/licenses/by/4.0/ The Creative Commons Public Domain Dedication waiver (http://creativecommons.org/publicdomain/zero/1.0/) applies to the data made available in this article, unless otherwise stated in a credit line to the data. 
of the PLA2G6 variant indicates that screening of Papillons intended for breeding is still recommended to avoid unintentional production of puppies with infantile NAD.

\section{Background}

Hereditary neuropathies in dogs frequently present at an early age and are generally progressive and fatal. Such diseases have been reported in numerous dog breeds (Online Mendelian Inheritance in Animals, OMIA) [1]. Identification of a causative mutation for these genetic diseases allows for a precise diagnosis, and can provide initial insight into therapeutic strategies that may prevent or reduce disease progression. As such, companion animals with hereditary diseases can serve as translational large animal models to investigate the potential safety and efficacy of novel treatments for human disease. However, screening and informed breeding are pivotal to reduce the widespread occurrence of disease-associated allelic variants in future generations of companion dogs.

Neuroaxonal dystrophy (NAD) represents a group of autosomal recessive degenerative neuropathies characterized histopathologically by 'spheroids' in the central nervous system and caused by one of a few dysfunctional genes in humans [2] and various animal species including dogs [1, 3]. In humans, variants in the phospholipase A2 group VI (PLA2G6) gene, which encodes a calcium-independent enzyme essential for membrane integrity, cause PLA2G6-associated neurodegeneration (PLAN) $[4,5]$.

An infantile NAD (OMIA \#: 002105-9615) was first identified in Papillion dogs in 1995 [6-11]. Clinical manifestations of ataxia, head tremor, difficulty rising, discordant gate, limb extension, paresis, inability to prehend food and water, and blindness are observed by 1-3 months of age. Axonal spheroids are found throughout the central nervous system but not in any peripheral nerves, and no iron accumulation was noted [7, 8, 11]. Because clinical signs are rapid and progressive, natural death occurs at a few months of age if not preceded by humane euthanasia. In the absence of a genetic test to identify carriers of this disease, breeders have excluded any Papillon parents and littermates of affected puppies from breeding to reduce the risk of producing affected puppies. Recently, a homozygous missense variant (XM_ 022424454.1:c.1579G > A) in PLA2G6 gene was identified in three Papillons with NAD in Japan [11]. In this report, we tested archived samples from Papillons with a clinicopathological diagnosis of NAD for the presence of the PLA2G6 missense variant and provide results of an initial genotyping survey of Papillons from North America and Europe.

\section{Materials and methods}

The Section of Medical Genetics and PennGen Laboratories had stored samples from four Papillons clinically diagnosed with NAD prior to 2015. These samples, as well as samples from their relatives, were analyzed for the published PLA2G6 missense variant [11]. Based upon the results, PennGen started to offer a genotyping assay for the PLA2G6 variant in late 2015. Either cheek swab or EDTA blood samples were accepted for genotyping. Genomic DNA was extracted using QIAamp Blood Mini Kit (Qiagen, Hilden, Germany). A TaqMan genotyping assay, as previously described [11], was used to determine the genotypes.

\section{Results and discussion}

The TaqMan genotyping assay for the XM_022424454.1: c.1579G > A variant in PLA2G6 readily differentiated the three genotypes. The four Papillons clinically affected with NAD were homozygous for the PLA2G6 variant, while samples from non-affected dogs were either homozygous for the wild-type allele or heterozygous for the previously published pathogenic variant [11].

Between October 2015 and December 2017, samples from 660 Papillons were received from North America and Europe (Table 1). Only three puppies homozygous for the pathogenic variant were found, with one each from USA, Canada, and Europe. All three Papillon puppies were clinically affected. The low number of affecteds is likely due to the fact that Papillon breeders are well aware of the typical clinical signs of NAD and may not feel the need to submit a sample for testing to confirm their presumptive diagnosis. Among the 660 dogs, $17.5 \%$ were heterozygous.

When the genotype screening test became available in late 2015, the demand was large and many breeders were interested in knowing if their Papillon was a carrier. Indeed, $79.5 \%$ of all requests indicated breeding and/or general screening as the reason for testing. Following screening, breeders were immediately able to avoid producing affecteds by mating clear (wild type; GG) to clear or clear to carrier (heterozygote; GA). While biased, the ability to undertake more selective breeding appeared to result in a decline in variant allele frequency within the first 3 years of screening (Table 2). As such, screening can help reduce the proportion of carriers in the population, reduce the need for future testing, and permit the breeding of many Papillons, particularly close relatives of an affected puppy that would not have been bred in the absence of testing in order to reduce potential disease risk.

As of late 2017, additional laboratories now offer the test, resulting in a dramatic reduction in the number of samples received by PennGen (only 14 Papillons with 5 carriers over the next 2 years). As of 2020, at least 10 laboratories worldwide (listed by the World Small Animal Veterinary Association, a web resource on DNA tests for hereditary diseases) offer genotyping for this variant as a specific test and/or as part of Papillon breed panel 
Table 1 Genotyping survey results from 2015 to 2017 of Papillon dogs from various geographic regions

\begin{tabular}{|c|c|c|c|c|c|}
\hline \multirow[t]{2}{*}{ Region } & \multirow{2}{*}{$\begin{array}{l}\text { Dogs } \\
\text { Tested }\end{array}$} & \multicolumn{3}{|c|}{ PLA2G6 Genotypes (c.1579G > A) } & \multirow{2}{*}{$\begin{array}{l}\text { Variant } \\
\text { allele } \\
\text { frequency }\end{array}$} \\
\hline & & Homozygous wild-type, GG & Heterozygous, GA & Homozygous variant, AA & \\
\hline United States & 552 & 461 & 90 & 1 & 0.083 \\
\hline Canada & 67 & 51 & 15 & 1 & 0.126 \\
\hline Europe & 41 & 29 & 11 & 1 & 0.158 \\
\hline Total (\%) & $660(100)$ & $541(81.9)$ & $116(17.5)$ & $3(0.4)$ & 0.092 \\
\hline
\end{tabular}

testing or dog panel testing $[12,13]$. A summary statement gathered by the Health Committee of Papillon Club of America indicates screening of an additional 2305 Papillons with a variant allele frequency of 0.047 in 2018-2019; this represents a decline of $50 \%$ over the prior 3 years. It should be noted that both our survey and that of the Club are biased by at least two factors. First, interested breeders with affected and carrier Papillons preferentially choose to screen their dogs, biasing the survey towards an increased allele frequency. Second, as the signs of juvenile NAD [14] are easily recognizable by breeders and clinicians, affected puppies are likely subject to immediate humane euthanasia. As such puppies may not be tested, the survey could be potentially biased towards a decrease in allele frequency.

Since 1995, there have been a few case reports of NAD in Papillons from the United Kingdom [6] and thereafter from Canada [10] and Japan [7-9, 11] suggesting a widespread distribution of this devastating disease trait in the breed. The Papillon breed has a relatively small breeding pool, with likely common inbreeding and international breedings. As the disease-related gene and variant were only recently identified [11], the prior inability to screen for this genetic disease resulted in its global dissemination. Notably, our results suggest that the widespread availability of screening tests for this PLA2G6 variant has resulted in successful reduction of the prevalence of the variant allele in the Papilion population.

The point variant XM_022424454.1:c.1579G > A in the PLA2G6 gene reported to be associated with NAD in Papillons results in an amino acid substitution of the 527th of 806 amino acids from a highly conserved alanine (as far back as zebrafish) to a threonine (XP_022280162.1: p.Ala527Thr) [11]. This missense variant resides in the serine lipase consensus sequence of the patatin domain of the $\mathrm{iPLA}_{2} \beta$ protein, and is not tolerated based on SIFT analysis [15]. The overall structure and functional domains of the iPLA $2 \beta$ enzyme are highly conserved between dog and human (90.8\%) and among other species. As expected for a missense variant, the $\mathrm{iPLA}_{2} \beta$ protein was expressed normally in the brain of Papillon puppies with NAD, but was predicted to be severely dysfunctional [11].

Recently, the genotype-phenotype associations in human patients with NAD and PLA2G6 variants (so called PLAN disorders) were reviewed $[4,5]$. Interestingly, missense variants were also commonly reported in human patients with PLAN. However, in humans, variants were found throughout the gene and were not associated with age of disease onset or clinical presentation of the four PLAN subtypes [4, 5]. While the affected Papillons present similarly to children with infantile NAD, an analogous variant has not yet been identified in human patients, although similar missense variants in the same domain are observed [4].

In human medicine, a variant allele frequency of 0.1 $(10 \%)$ is considered extremely high and is very rarely seen, except in a few select populations for very select variants [16]. While the survey of canine infantile NAD presented here is biased, our findings together with the initial report from Japan, clearly document the worldwide distribution and high prevalence of the variant PLA2G6 allele in the Papillon population. Such findings are not unusual in specific dog breeds, as common ancestry, founder effects, and international breeding [16] can lead to high frequencies of a genetic disease in afflicted breeds. A common ancestor for the PLA2G6 gene variant has not been identified.

Table 2 Change of genotyping results from 2015 to 2017 of Papillon dogs

\begin{tabular}{|c|c|c|c|c|c|}
\hline \multirow[t]{2}{*}{ Year } & \multirow{2}{*}{$\begin{array}{l}\text { Dogs } \\
\text { Tested }\end{array}$} & \multicolumn{3}{|c|}{ PLA2G6 Genotypes (c.1579G > A) } & \multirow{2}{*}{$\begin{array}{l}\text { Variant } \\
\text { allele } \\
\text { frequency }\end{array}$} \\
\hline & & Homozygous wild-type, GG & Heterozygous, GA & Homozygous variant, AA & \\
\hline 2015 & 97 & 69 & 26 & 2 & 0.154 \\
\hline 2016 & 479 & 400 & 78 & 1 & 0.083 \\
\hline 2017 & 84 & 72 & 12 & 0 & 0.071 \\
\hline Total (\%) & $660(100)$ & 541 (81.9) & $116(17.5)$ & $3(0.4)$ & 0.092 \\
\hline
\end{tabular}


It should be noted that once a validated pathogenic variant is identified in a population, one can safely breed heterozygotes for the variant (asymptomatic carriers) to homozygous wildtype dogs (clear dogs, normals). Subsequent testing of offspring intended for breeding will then prevent further production of any affected puppies and reduce or eliminate spreading of the variant allele in the breed population. Such strategies also highlight the importance of maintaining a broader gene pool in a small breed population. Although limited in scope, the observed decline between 2015 and 2019 that likely occured as a result of screening of the breeding population and consequent informed breeding practices, shows the keen interest and willingness of breeders to follow practices that will avoid production of any puppies affected by NAD.

In conclusion, this survey from North America and Europe using samples collected between 2015 and 2017, combined with data obtained from other laboratories between 2017 and 2019 documents the widespread presence of the PLA2G6 variant in the Papillon population. Despite the apparent declining prevalence of the PLA2G6 variant over the past years, screening of Papillons intended for breeding is recommended unless cleared by parent testing.

\section{Abbreviations}

NAD: Neuroaxonal dystrophy; PLAN: PLA2G6-associated neurodegeneration; OMIA: Online Mendelian Inheritance in Animals

\section{Acknowledgements}

The support and participation of members of the Papillon Club of America are greatly appreciated. We also thank Leslie King PhD for scientific editing of manuscript.

\section{Authors' contributions}

KR did the DNA testing, UG and KR developed the concept, analyzed the data, and drafted and approved the final manuscript.

\section{Funding}

Supported in part by the Papillon Club of America and the NIH grant (OD 010939).

\section{Availability of data and materials}

The datasets used and/or analyzed during the current study are available from the corresponding author on reasonable request.

Ethics approval and consent to participate

Not applicable as only data from samples submitted for clinical diagnostics were used.

\section{Consent for publication}

Not applicable.

\section{Competing interests}

The authors are or were associated with the not-for-profit PennGen Laboratories, which offer certain DNA and metabolic testing for hereditary diseases in dogs and cats.
Received: 24 September 2020 Accepted: 19 November 2020

Published online: 30 November 2020

\section{References}

1. OMIA - Online Mendelian Inheritance in Animals. https://omia.org/. Accessed 18 August 2020.

2. Nardocci N, Zorzi G. Axonal dystrophies. In: Dulac O, Lassonde M, Sarnat HB, editors. Handbook of Clinical Neurology (Volume 113): Elsevier; 2013. p. 1919-24. https://doi.org/10.1016/B978-0-444-59565-2.00062-9.

3. Lorenz MD, Coates JR, Kent M. Tetraparesis, hemiparesis, and ataxia. In: Lorenz MD, Coates JR, Kent M, editors. Handbook of Veterinary Neurology (Fifth Edition): W.B. Saunders; 2011. p. 162-249. https://doi.org/10.1016/ B978-1-4377-0651-2.10007-4.

4. Guo Y, Tang B, Guo J. PLA2G6-associated neurodegeneration (PLAN): review of clinical phenotypes and genotypes. Front Neurol. 2018:9:1100. https://doi. org/10.3389/fneur.2018.01100.

5. Chu Y, Lin H, Chen P, Lin C. Genotype-phenotype correlations of adult-onset PLA2G6-associated Neurodegeneration: case series and literature review. BMC Neurol. 2020;20(1):101. https://doi.org/10.1186/s1 2883-020-01684-6.

6. Franklin RJM, Jeffery ND, Ramsey IK. Neuroaxonal dystrophy in a litter of papillon pups. J Small Anim Pract. 1995 Oct;36(10):441-4. https://doi.org/10. 1111/j.1748-5827.1995.tb02774.x.

7. Nibe K, Kita C, Morozumi M, Awamura Y, Tamura S, Okuno S, et al. Clinicopathological features of canine neuroaxonal dystrophy and cerebellar cortical abiotrophy in papillon and papillon-related dogs. J Vet Med Sci. 2007:69(10):1047-52. https://doi.org/10.1292/jvms.69.1047.

8. Nibe K, Nakayama H, Uchida K. Immunohistochemical features of dystrophic axons in Papillon dogs with Neuroaxonal dystrophy. Vet Pathol. 2009 May: 46(3):474-83. https://doi.org/10.1354/vp.08-VP-0156-U-FL.

9. Tamura S, Tamura Y, Uchida K. Magnetic resonance imaging findings of neuroaxonal dystrophy in a papillon puppy. J Small Anim Pract. 2007 Aug; 48(8):458-61. https://doi.org/10.1111/j.1748-5827.2006.00304.x.

10. Diaz JV, Duque C, Geisel R. Neuroaxonal dystrophy in dogs: case report in 2 litters of Papillon puppies. J Vet Intern Med. 2007 May;21 (3):531-4. https://doi.org/10.1111/j.1939-1676.2007.tb03002.x.

11. Tsuboi M, Watanabe M, Nibe K, Yoshimi N, Kato A, Sakaguchi M, et al. Identification of the PLA2G6 c.1579G>A missense mutation in Papillon dog with neuroaxonal dystrophy using whole exome sequencing analysis. PloS One. 2017;12(1):e0169002. https://doi.org/10.1371/journal.pone.0169002.

12. Slutsky J, Raj K, Yuhnke S, Bell J, Fretwell N, Hedhammar A, et al. A web resource on DNA tests for canine and feline hereditary diseases. Vet J. 2013; 197(2):182-7. https://doi.org/10.1016/j.tvj.2013.02.021.

13. Penn Vet | Tests Worldwide. http://research.vet.upenn.edu/WSAVALabSearch. Accessed 18 August 2020.

14. NAD Stats Worldwide 12-31-2019 - 1b6eff_ 405947e8370e41d09b4eb8a3352c7c6e.pdf. https://798ba9dc-e88e-4be88a24-e610198b3367.filesusr.com/ugd/1 b6eff_405947e8370e41d09b4 eb8a3352c7c6e.pdf. Accessed 18 August 2020.

15. Vaser R, Adusumalli S, Leng SN, Sikic M, Ng PC. SIFT missense predictions for genomes. Nat Prot. 2015;11(1):1-9. https://doi.org/10.1038/nprot.2015.123.

16. Korf BR, Pyeritz RE, Grody WW. Nature and frequency of genetic disease. In: Pyeritz RE, Korf BR, Grody WW, editors. Emery and Rimoin's Principles and Practice of Medical Genetics and Genomics (Seventh Edition): Academic Press; 2019. p. 47-51. https://doi.org/10.1016/B978-0-12-812537-3.00003-2.

\section{Publisher's Note}

Springer Nature remains neutral with regard to jurisdictional claims in published maps and institutional affiliations. 